\title{
ATIVIDADES INVESTIGATIVAS NO ENSINO DE CIÊNCIAS: ASPECTOS HISTÓRICOS E DIFERENTES ABORDAGENS
}

RESUMO: Neste estudo, realizamos uma discussão sobre as diferentes abordagens acerca da utilização de atividades investigativas no ensino de Ciências, apresentadas na visão de diversos autores. As atividades investigativas apresentam denominações distintas na literatura, como: inquiry, ensino por investigação, ensino por projetos, dentre outras. Os autores concordam que essa perspectiva de ensino proporciona ao aluno, além $\mathrm{da}$ aprendizagem de conceitos e procedimentos, o desenvolvimento de diversas habilidades cognitivas e a compreensão da natureza da ciência. $\mathrm{O}$ estudo apresenta características apontadas por diversos autores, no que se refere a atividades investigativas, e visa mostrar o caráter não conclusivo que essa abordagem de ensino apresenta. Além das diferentes abordagens, também foram enfatizados os aspectos históricos que envolvem o ensino com a utilização de atividades investigativas.

Palavras-chave: Ensino de ciências, atividades investigativas, aspectos históricos.

\section{INVESTIGATIVE ACTIVITIES IN SCIENCE TEACHING: HISTORICAL ASPECTS AND DIFFERENT APPROACHES}

ABSTRACT: This paper presents a historical discussion about the use of investigative activities in science teaching, and the different approaches of this teaching methodology according to several authors. The inquiry activities have distinct denominations in the literature: inquiry, teaching through investigation, teaching through projects, among others. The authors agree that this teaching approach allows students to develop several cognitive skills and understand the nature of science, in addition to learning concepts and procedures. The paper highlights the aspects discussed by several authors when addressing investigative activities, and also the non-conclusive character of the approach.

Keywords: Science Teaching, Investigative activities, Historical aspects.

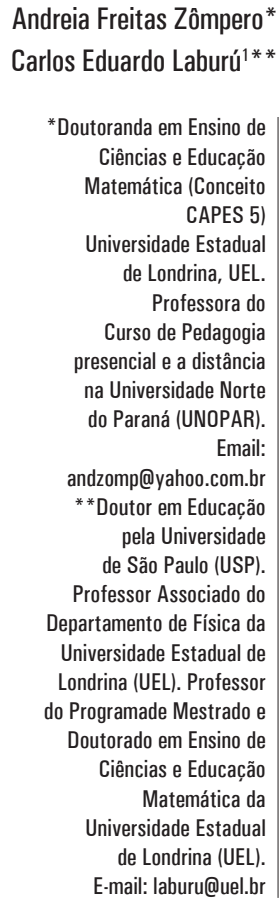




\section{INTRODUÇÃO}

Durante o período compreendido entre a segunda metade do século XIX e os dias atuais, o ensino de Ciências apresentou diferentes objetivos que tiveram como base, principalmente, as mudanças vigentes na sociedade em suas diferentes épocas, considerando aspectos políticos, históricos e filosóficos.

Muitas das tendências do ensino de Ciências não tiveram uma relevância significativa no Brasil, contrariamente ao que ocorreu em países da Europa e nos Estados Unidos. Dentre essas tendências, pode ser citado o ensino por investigação, conhecido também como "inquiry”, que recebeu grande influência do filósofo e pedagogo americano John Dewey.

$\mathrm{Na}$ literatura, encontram-se diferentes conceituações de inquiry, como: ensino por descoberta; aprendizagem por projetos; questionamentos; resolução de problemas, dentre outras. A perspectiva do ensino com base na investigação possibilita o aprimoramento do raciocínio e das habilidades cognitivas dos alunos, e também a cooperação entre eles, além de possibilitar que compreendam a natureza do trabalho científico. Nas linhas que se seguem, optamos por utilizar o termo atividades investigativas quando nos referirmos a essa perspectiva de ensino.

$\mathrm{Na}$ literatura relativa ao ensino de Ciências, há a informação de que existem muitos pesquisadores que trabalham nessa área e apresentam diferentes abordagens para o ensino investigativo. Neste estudo, nossa preocupação foi verificar que características essas atividades de ensino devem apresentar para serem consideradas como investigativas. Interessados na aplicação de atividades investigativas no ensino de Ciências, optamos por realizar um estudo mais detalhado sobre as diversas abordagens apresentadas por autores pesquisadores da área, com o intuito de encontrar pontos de convergência entre elas, os quais nos possibilitem uma reflexão sobre os denominadores comuns encontrados, para que possamos designar uma determinada atividade em Ciências como de caráter investigativo. Admitimos ser importante tal reflexão para proporcionar maior clareza quanto aos fundamentos das atividades consideradas investigativas na perspectiva de diferentes autores, o que vai permitir não só direcionar o trabalho de professores que as empregam na educação básica ou superior, como também nortear pesquisas na área. Para tanto, apresentamos as características de ensino com base na investigação, na ótica de diversos autores, para que nos fosse possível analisá-las e tecer possíveis comparações. Antes, porém, realizamos um estudo sobre a trajetória do ensino por investigação, salientando os aspectos históricos e ressaltando as influências que essa metodologia de ensino recebeu em diversos períodos históricos.

\section{A PEDAGOGIA PROGRESSISTA E SUA INFLUÊNCIA NO ENSINO DE CIÊNCIAS}

A preocupação em estimular atividades investigativas na educação científica aparece ainda no século XIX. A perspectiva de inquiry, assim denominada 
nos Estados Unidos, foi predominante na educação americana. Tal perspectiva recebeu influência das ideias do filósofo John Dewey.

De acordo com Wong e Pugh (2001), Dewey tornou-se símbolo para as ideias progressistas na educação científica. Outras denominações da Pedagogia Progressista encontradas na literatura são: Pedagogia Ativa, Escola Ativa, Escola Nova, Escola do Trabalho. A Pedagogia Progressista surgiu nos Estados Unidos como crítica à Pedagogia tradicional defendida por Herbart, filósofo e pedagogo, que viveu no século XIX. De acordo com ele, o ensino deve ser organizado com base em três conceitos principais: governo, disciplina e instrução educativa. O governo refere-se às regras externas que fazem com que o aluno mantenha-se atento ao assunto estudado. Para que isso seja efetivado é possível aplicar castigos e ameaças ao aluno. A disciplina visa à formação do caráter para que o aluno desenvolva e reflita sobre os aspectos morais. Por fim, a instrução educativa consiste em educar o aluno para que desperte interesse em aprender. Para Herbart, a instrução é assegurada pela disciplina e pelo governo.

No final do século XIX, surgiu o Movimento Progressista, que era contrário às ideias de Herbart e dos jesuítas. Os adeptos dessa nova pedagogia defendiam o ensino centrado na vida, na atividade, aliando teoria e prática, sendo o aluno participante ativo de seu processo de aprendizagem. Dewey foi precursor dessas ideias. Seu nome tem sido associado à aprendizagem por projetos e por resolução de problemas.

A influência dessas ideias pode ser notada na educação a partir da década de 1970, com a ascensão do cognitivismo. Outro aspecto relevante a ser considerado é que as ideias progressistas enfatizam a importância das interações socioculturais para a aprendizagem. Nesse aspecto, é possível uma relação entre a pedagogia de Dewey e as ideias de Vigotsky, o qual também defende elementos sociais na aprendizagem (WONG e PUGH, 2001).

A ideia central de Dewey que tem influência na educação científica é a "experiência". Este termo é frequentemente mal entendido, pois é comum as pessoas associarem a experiência com aulas práticas e, desse modo, estas seriam a solução para a aprendizagem de Ciências, por exemplo, as aulas deveriam ser mais experimentais ao invés de memorizar conteúdos. Por isso, esta definição de experiência não é condizente com a proposta do filósofo.

De acordo com Dewey (1980), no universo há um conjunto infinito de elementos que se relacionam da maneira mais diversa possível. Tudo existe em função dessas relações. Isso evidentemente ocorre também com as pessoas. Quando a criança chega à escola, ela já vivenciou muitas experiências, por isso, esse agir e reagir amplia-se, e as experiências se reconstroem por meio das reflexões. $\mathrm{Na}$ vida cotidiana as experiências são realizadas constantemente. Para o filósofo, experiência e aprendizagem não podem ser separadas.

Um exemplo de como as experiências atuam na aprendizagem, promovendo modificações significativas na compreensão do aprendiz é: 
Uma árvore pode ser somente um objeto da experiência visual, pode passar a ser percebida de outro modo se entre ela e a pessoa se processarem outras experiências como a utilidade, aspectos medicinais, econômicos, etc.. Isso fará o indivíduo perceber a árvore de modo diferente. Depois dessa experiência, o indivíduo e a árvore são diferentes do que eram antes. (DEWEY, 1980, p: 114)

A experiência se adquire a partir de um conjunto de vivências (ROSITO, 2008). Nesse sentido, quando a experiência educativa é refletida, a aquisição de conhecimento será seu resultado natural, portanto, a experiência dá significado à vida. Ainda com base em Dewey (1980), a contínua reorganização da experiência pela reflexão é característica particular da vida humana. A educação consiste nessa contínua reorganização, que promove uma melhoria na qualidade da experiência para novas aprendizagens.

Outro conceito chave na teoria de Dewey, que se relaciona com a educação cientifica, é a antecipação. Na teoria Pedagógica Progressista desse filósofo, a antecipação é o centro das experiências educativas. A ideia pode criar antecipações.

Ideias inspiram ações. Ações as fazem ter significações e valores. Ideias geram antecipação, que são previsões sobre o que pode ser descoberto e revelado para a classe. As antecipações geram as experiências (WONG e PUGH, 2001).

\section{A EDUCAÇÃO CIENTÍFICA E AS ATIVIDADES INVESTIGATIVAS NOS SÉCULOS XIX E XX}

De acordo com Deboer (2006), até a segunda metade do século XIX, a educação científica tinha um currículo clássico que enfatizava, principalmente, o estudo de Matemática e de Gramática. No entanto, alguns cientistas europeus e americanos começaram a defender a ideia de que a Ciência era diferente de outras disciplinas escolares, por oferecer práticas de lógica indutiva.

Conforme Chalmers (2000), a Ciência indutiva começa com procedimentos de observações detalhadas para construir generalizações. Por isso, os estudantes tinham que aprender a observar o mundo natural e formular conclusões a partir de suas observações. Ainda de acordo com o referido autor, essa abordagem para o Ensino de Ciências, considerando a indução, foi uma justificativa para o surgimento de práticas que envolviam a utilização do laboratório.

Nesse período, o laboratório e o ensino, utilizando processos investigativos, receberam apoio do cientista e filósofo positivista, do século XIX, Herbert Spencer. Para ele, a utilização do laboratório poderia promover a melhor compreensão dos fenômenos naturais. A observação do mundo e as atividades de laboratório fornecem informações claras e precisas sobre a natureza que não se encontram nos livros. Spencer considerava a Física, a Química e a Biologia essenciais para a formação humana. As ideias positivistas de Spencer influenciaram práticas pedagógicas no Ensino de Ciências, resultando na aplicação do método científico no ensino: observação, controle, previsão (ISKANDAR \& LEAL, 2002).

O químico Charles Eliot também defendeu a utilização do laboratório 
para as práticas investigativas, argumentando que o estudo de Química poderia desenvolver nos estudantes habilidades de pensamento, incluindo comparação, discriminação e indução. Ainda para Eliot, o laboratório poderia ser usado para verificar princípios da química (DEBOER, 2006).

No século XIX, pode-se concluir, de acordo com Smith (apud DEBOER, 2006), que o ensino com base em perspectivas investigativas apresentou três fases: descoberta ou abordagem heurística, na qual os estudantes teriam que explorar o mundo natural; a verificação, na qual os alunos teriam que confirmar fatos ou princípios científicos por meio da utilização do laboratório, e o inquiry. Neste último caso, os alunos não teriam que descobrir algo, mas por meio da utilização de método científico, os estudantes teriam que procurar soluções para questões que eles não sabiam a resposta.

A inclusão do inquiry na educação científica foi recomendada por Dewey a partir do livro Logic: The Theory of Inquiry, publicado em 1938. Para este filósofo e pedagogo, havia na educação científica muita ênfase no ensino de fatos, sem estimular o raciocínio e as habilidades mentais. Para Dewey, o aluno deveria participar ativamente de sua aprendizagem, por isso, os alunos deveriam propor um problema para investigarem aplicando seus conhecimentos de ciências aos fenômenos naturais (BARROW, 2006). Esse mesmo autor, afirma que Dewey modificou sua interpretação anterior sobre os passos do método científico para realizar seu objetivo de pensamento reflexivo. Os passos seriam: apresentação de problema, formação de hipótese, coleta de dados durante o experimento e formulação de conclusão. Os problemas a serem estudados deveriam estar de acordo com o desenvolvimento intelectual, as capacidades cognitivas dos estudantes e com as experiências dos mesmos. A ideia aqui era preparar os alunos para serem pensadores ativos, em busca de respostas e não apenas disciplinar o raciocínio indutivo.

A educação científica, na primeira metade do século XX, teve seu objetivo principal voltado aos valores sociais, devido ao crescimento da urbanização, da imigração, problemas relacionados com a saúde pública. Neste sentido, o inquiry foi visto como um modo de desenvolver habilidades necessárias para resolver problemas de relevância social, ao invés de apenas desenvolver nos alunos habilidades de raciocínio. Essas ideias estavam também baseadas na filosofia de Dewey. Segundo ele, para preparar os estudantes para a vida, a educação formal deveria dar a eles habilidades para formular questões significativas sobre os problemas sociais.

Em 1950, os cientistas, educadores e líderes industriais, argumentaram que o Ensino de Ciências tinha perdido o seu rigor acadêmico e não estava possibilitando o desenvolvimento intelectual dos alunos, já que o ensino estava enfatizando aspectos de relevância social. A educação científica, naquele período, estava centrada demais no aluno e, por isso, havia perdido o rigor acadêmico (DEBOER, 2006).

Essa preocupação com a educação científica, nos Estados Unidos, culminou com o lançamento do satélite Sputinik pelos russos. Por isso, a educação científica foi outra vez voltada para o rigor acadêmico do século XIX, enfatizan- 
do os processos da ciência com a preocupação de formar cientistas, para garantir a segurança dos americanos. A ênfase, novamente, encontrava-se nos processos de Ciências e habilidades individuais como: observar; classificar; inferir, e controlar variáveis (BARROW, 2006).

Nessa reforma curricular, Josef Schwab, o principal pensador envolvido, considerava que conteúdo e prática são inseparáveis na educação científica. Para ele, os alunos deveriam aprender como os cientistas chegam às conclusões, e não terem tais conclusões prontas dadas pelo professor. A educação científica proposta por Schwab é muito parecida com a proposta do século XIX. A diferença é que, naquele século, havia uma preocupação com o desenvolvimento pessoal do aluno e, para Schwab, a preocupação foi com o desenvolvimento da nação americana (DEBOER, 2006). Além disso, para Schwab, a utilização de investigação no ensino permite aos alunos entenderem os processos da Ciência.

Muitas críticas foram apontadas para o ensino por descoberta e voltadas à formação de cientistas (DEBOER, 2006). Devido a tal situação, tanto no Brasil como nos demais países, começaram a ganhar força, nos anos finais da década de 1970, as ideais construtivistas. Surge nesse período o Movimento das Concepções Alternativas, o qual tinha como principal objeto de estudo as ideias que os alunos tinham sobre os fenômenos naturais, pelo fato de que estas concepções interferem no processo de aprendizagem.

A partir dessa proposta, o objetivo da educação científica foi principalmente fazer com que os alunos mudassem suas concepções alternativas de modo a se tornarem coerentes com o conhecimento científico.

Ainda na década de 1970, com os agravos causados ao meio ambiente, o Ensino de Ciências passou a novamente ter a preocupação de propor uma educação que levasse em conta os aspectos sociais relativos ao desenvolvimento científico e tecnológico. Essa abordagem iniciou-se na Grã-Bretanha e desenvolveu-se até a década de 1980 por meio de debates de ideias, até atingir as práticas pedagógicas, envolvendo textos, currículos e processos de avaliação (GOUVEIA e LEAL, 2001).

Nessa perspectiva, as atividades investigativas eram utilizadas como orientação para ajudar os estudantes a pesquisar problemas sociais como o aquecimento global, a poluição, dentre outros. Sendo assim, o objetivo da educação científica era o entendimento dos conteúdos, dos valores culturais, da tomada de decisões relativas ao cotidiano e à resolução de problemas.

No final dos anos 1980, foi elaborado um documento nos Estados Unidos intitulado Science For All Americans. Nesse documento, os autores recomendavam que o Ensino de Ciências deveria ser coerente com a natureza da investigação científica. Os estudantes, então, teriam que aprender determinados procedimentos como: observar, anotar, manipular, descrever, fazer perguntas e tentar encontrar respostas para as perguntas. Posteriormente, em 1996, houve a publicação de outro documento intitulado National Science Education Standards, em que são propostas algumas orientações para a Alfabetização Científica, reconhecendo também a importância do ensino por investigação (BARROW, 2006). 
No Brasil, a abordagem do ensino envolvendo atividades de investigação é encontrada nos Parâmetros Curriculares Nacionais (1997). No entanto, de acordo com Sá et al (2007), o Ensino de Ciências por investigação no Brasil ainda não está bem estabelecido. Outro aspecto que pode ser ressaltado é a dificuldade de os professores utilizarem tanto as práticas de laboratório como as atividades de investigação com os alunos, por se sentirem inseguros em realizar experimentos, em gerenciar a turma e com a utilização de materiais no laboratório. (BORGES, 2002).

Conforme é possível perceber, a ideia de ensino por investigação passou por modificações em função das necessidades políticas, econômicas e sociais pelas quais a sociedade passou durante várias décadas. Vimos que há uma ênfase maior em utilização de atividades investigativas pelos americanos, sendo que no Brasil essa tendência é pouco predominante, e também pouco enfatizada nos documentos oficias de ensino. No entanto, há algumas instituições de ensino, principalmente as particulares, que afirmam trabalhar com a proposta investigativa

\section{DIFERENTES ABORDAGENS DE ENSINO PARA UTILIZAÇÃO DE ATIVIDADES INVESTIGATIVAS}

Conforme já citamos, existem várias denominações para esta perspectiva de ensino, como inquiry, aprendizagem por descoberta, resolução de problemas, projetos de aprendizagem, ensino por investigação. Além das diferentes conceituações, existem também várias abordagens para o ensino com atividades de investigação (inquiry). As atividades investigativas não são realizadas, atualmente, por meio de etapas, levando os alunos a realizá-las de modo algorítmico, como em um suposto método científico. O ensino por investigação, que leva os alunos a desenvolverem atividades investigativas, não tem mais, como na década de 1960, o objetivo de formar cientistas. Atualmente, a investigação é utilizada no ensino com outras finalidades, como o desenvolvimento de habilidades cognitivas nos alunos, a realização de procedimentos como elaboração de hipóteses, anotação e análise de dados e o desenvolvimento da capacidade de argumentação.

Nesta seção, serão apresentadas algumas das diferentes abordagens desta metodologia de ensino na visão de diferentes autores. Em todas elas, as atividades investigativas devem partir de problemas.

No quadro 1, estão resumidas algumas propostas. 
Quadro 1: Resumo analítico de pressupostos do ensino por investigação

\begin{tabular}{|c|c|c|c|c|c|}
\hline $\begin{array}{l}\text { MOMENTOS DO } \\
\text { PROCESSO }\end{array}$ & $\begin{array}{l}\text { DEL CARMEN } \\
\text { (1988) }\end{array}$ & $\begin{array}{l}\text { OLVERA } \\
\text { (1992) }\end{array}$ & $\begin{array}{l}\text { ZABALA } \\
\text { (1992) }\end{array}$ & $\begin{array}{c}\text { GIL } \\
\text { (1993) }\end{array}$ & $\begin{array}{l}\text { GARCIA } \\
(1993)\end{array}$ \\
\hline $\begin{array}{l}\text { ESCOLHA DO } \\
\text { OBJETO DE } \\
\text { ESTUDO E DO } \\
\text { PROBLEMA }\end{array}$ & $\begin{array}{l}\text { Planejamento e } \\
\text { clarificação do } \\
\text { problema }\end{array}$ & $\begin{array}{l}\text { Escolha do } \\
\text { objeto de } \\
\text { estudo }\end{array}$ & $\begin{array}{l}\text { Explicitação } \\
\text { de perguntas }\end{array}$ & $\begin{array}{c}\text { Situação } \\
\text { problemática. } \\
\text { Precisar o } \\
\text { problema }\end{array}$ & $\begin{array}{l}\text { Contato inicial, } \\
\text { formulação do } \\
\text { problema }\end{array}$ \\
\hline $\begin{array}{c}\text { EXPRESSÃO } \\
\text { DAS IDEIAS } \\
\text { DOS ALUNOS. } \\
\text { EMISSÃO DE } \\
\text { HIPÓTESES. }\end{array}$ & $\begin{array}{l}\text { Definição, } \\
\text { hipóteses de } \\
\text { trabalho }\end{array}$ & $\begin{array}{l}\text { Definição de } \\
\text { hipóteses }\end{array}$ & $\begin{array}{l}\text { Hipóteses, } \\
\text { respostas } \\
\text { intuitivas }\end{array}$ & $\begin{array}{l}\text { Construção } \\
\text { de modelos e } \\
\text { hipóteses }\end{array}$ & $\begin{array}{l}\text { Interação com } \\
\text { as informações } \\
\text { dos alunos }\end{array}$ \\
\hline $\begin{array}{l}\text { PLANEJAMENTO } \\
\text { DA } \\
\text { INVESTIGAC̣ÃO }\end{array}$ & $\begin{array}{c}\text { Planejamento da } \\
\text { investigação e } \\
\text { instrumentos }\end{array}$ & $\begin{array}{l}\text { Planejamento da } \\
\text { investigaçãa }\end{array}$ & $\begin{array}{c}\text { Fontes de } \\
\text { informações, } \\
\text { tomada de dados }\end{array}$ & & $\begin{array}{c}\text { Elaboração } \\
\text { de estratégias } \\
\text { para incorporar } \\
\text { novas informações }\end{array}$ \\
\hline $\begin{array}{c}\text { NOVA } \\
\text { INFORMAC̣ÃO }\end{array}$ & $\begin{array}{c}\text { Aplicação de } \\
\text { instrumentos de } \\
\text { investigação }\end{array}$ & $\begin{array}{l}\text { Materiais e } \\
\text { instrumentos }\end{array}$ & $\begin{array}{l}\text { Tomada } \\
\text { de dados }\end{array}$ & $\begin{array}{c}\text { Realização } \\
\text { de atividades }\end{array}$ & $\begin{array}{c}\text { Interação da } \\
\text { informação nova } \\
\text { e pré-existente }\end{array}$ \\
\hline $\begin{array}{c}\text { INTERPRETAÇÃO } \\
\text { DOS } \\
\text { RESULTADOS } \\
\text { E CONCLUSÕES }\end{array}$ & $\begin{array}{l}\text { Comunicação, } \\
\text { discussão, } \\
\text { valoração }\end{array}$ & $\begin{array}{l}\text { Comunicação da } \\
\text { investigação. } \\
\text { Publicação de } \\
\text { trabalhos }\end{array}$ & $\begin{array}{c}\text { Seleção, } \\
\text { classificação } \\
\text { de dados e } \\
\text { conclusão }\end{array}$ & $\begin{array}{c}\text { Interpretação } \\
\text { dos resultados, } \\
\text { relação hipóteses } \\
\text { e corpo teórico }\end{array}$ & \\
\hline $\begin{array}{c}\text { EXPRESSÃO E } \\
\text { COMUNICAC̣ÃO } \\
\text { DOS } \\
\text { RESULTADOS }\end{array}$ & $\begin{array}{l}\text { Comunicaçãa, } \\
\text { discussão, } \\
\text { valoração }\end{array}$ & $\begin{array}{l}\text { Comunicação da } \\
\text { investigação. } \\
\text { Publicação de } \\
\text { trabalhos }\end{array}$ & $\begin{array}{c}\text { Expressão } \\
\text { Comunicação }\end{array}$ & $\begin{array}{l}\text { Comunicação } \\
\text { Intercâmbio } \\
\text { entre equipes }\end{array}$ & $\begin{array}{c}\text { Elaboração } \\
\text { da informação } \\
\text { existente. } \\
\text { Recapitulação }\end{array}$ \\
\hline $\begin{array}{l}\text { RECAPITULAÇÃO } \\
\text { E SÍNTESE }\end{array}$ & $\begin{array}{c}\text { Sínteses } \\
\text { Identificação } \\
\text { Modelos } \\
\text { explicativos }\end{array}$ & & & $\begin{array}{c}\text { Sínteses, } \\
\text { esquemas, } \\
\text { Mapas } \\
\text { conceituais }\end{array}$ & \\
\hline $\begin{array}{l}\text { APLICAÇÃO } \\
\text { A NOVAS } \\
\text { SITUAÇÕES }\end{array}$ & & & Generalização & $\begin{array}{l}\text { Possibilidades } \\
\text { de aplicação }\end{array}$ & $\begin{array}{c}\text { Aplicação } \\
\text { Generalização }\end{array}$ \\
\hline METACOGNIC̣̃̃O & & & & & $\begin{array}{c}\text { Reflexão sobre } \\
\text { o processo }\end{array}$ \\
\hline $\begin{array}{l}\text { ATUAÇÃO } \\
\text { NO MEIO }\end{array}$ & & $\begin{array}{l}\text { Proposta de } \\
\text { intervenção, } \\
\text { Ações }\end{array}$ & & & \\
\hline
\end{tabular}

Fonte: Rodriguez et al, 1995. p: 12.

Ao analisar o quadro, na aplicação dessa metodologia, evidenciamos a existência de vários pontos em comum. Os autores citados admitem que para uma proposta investigativa deve haver um problema para ser analisado, a emissão de hipóteses, um planejamento para a realização do processo investigativo, visando a obtenção de novas informações, a interpretação dessas novas informações e a 
posterior comunicação das mesmas.

Com relação ao problema a ser investigado, Olvera (apud Rodrigues 1995) propõe que o mesmo seja escolhido em função dos interesses dos alunos. Rodriguez (1995), ao comparar os diferentes autores citados no quadro, salienta que, independente de a formulação do problema partir do aluno ou do professor, é necessário que os alunos se interessem pelo problema a ser investigado, de forma a serem motivados a resolvê-lo.

Um aspecto relevante que pode ser observado é a necessidade de que as atividades investigativas proporcionem aos estudantes o contato com as novas informações. Nas atividades investigativas, é necessária a comunicação das novas informações obtidas pelos alunos. Essa divulgação dos resultados poderá ser realizada por meio da oralidade ou da escrita.

Em outra abordagem, Gil Perez e Castro (1996) ressaltam que as atividades de investigação devem compreender as seguintes características: apresentar aos alunos situações problemáticas abertas, em um nível de dificuldade adequado à zona de desenvolvimento potencial dos educandos; favorecer a reflexão dos alunos sobre a relevância das situações-problema apresentadas; emitir hipótese como atividade indispensável à investigação científica; elaborar um planejamento da atividade experimental; contemplar as implicações CTS do estudo realizado; proporcionar momentos para a comunicação do debate das atividades desenvolvidas; potencializar a dimensão coletiva do trabalho científico.

Outros autores, como Rodriguez et al (1995), vão além da apresentação de características e propõem algumas etapas para as atividades investigativas. Dentre elas estão: a elaboração do problema pelos alunos; elaboração de hipóteses; planejamento da investigação; contato com novas fontes de informação, incluindo experimentos; leitura de materiais informativos; visitas; interpretação e conclusão dos resultados. Após essas etapas, o aluno deverá expressar seus resultados ao grupo e aplicar o conhecimento a novas situações.

De acordo com Watson (2004), as atividades investigativas devem proporcionar o conhecimento dos processos da Ciência. O autor enfatiza que os alunos devem perceber evidências e que esse conceito precisa ser desenvolvido com os educandos, pois os procedimentos científicos são baseados nelas. O mesmo autor afirma que, nas atividades investigativas, os alunos podem, a partir da situação problema, desenvolver planejamento de resolução, reunir evidências, elaborar inferências. Além disso, durante as atividades, é possível aos alunos desenvolverem a argumentação.

Para Newman et al (2004), as atividades de investigação devem envolver o uso de evidência, lógica e imaginação na elaboração de explicações sobre o mundo natural. Este autor, assim como o anteriormente citado, salienta o reconhecimento de evidência pelos alunos, como parte do processo investigativo. A investigação ajuda os alunos a alcançar o entendimento da ciência e desenvolver o raciocínio científico. De acordo com o Newman et al (2004), quando os alunos estão engajados na investigação, eles descrevem objetos e eventos, fazem perguntas, constroem explicações e expõem essas explicações para os demais alunos. Nesse sentido, 
Borges (2002) salienta que, em uma atividade de investigação realizada em uma sala de aula, o estudante deve ser colocado frente a uma situação na qual ele seja solicitado a fazer algo mais do que se lembrar de uma fórmula ou de uma solução já utilizada em uma situação semelhante.

Conforme é possível verificar, o ensino por meio de atividades de investigação apresenta diferentes abordagens de acordo com os autores estudados. Nos Estados Unidos, as atividades investigativas são bastante recomendadas na Educação Científica. De acordo com Bybee (2006), em função dessas diferentes abordagens, foram divulgadas, no documento oficial de ensino americano, intitulado National Research Council (2000), as principais características que devem existir no ensino com atividades investigativas, as quais são: engajamento dos estudantes na atividade; priorização de evidências; formulação de explicações para as evidências; articulação das explicações com o conhecimento científico; comunicação e justificação das explicações.

As características aqui mencionadas neste documento são compatíveis com as apresentadas por alguns autores como, por exemplo: Olvera (apud Rodrigues 1995), quanto à necessidade do engajamento nas atividades; Watson e Newman (2004), sobre a priorização de evidências; Gil (1993), em relação à formulação de explicações sobre o fenômeno em estudo e Gil (1996), quanto à articulação das explicações dos alunos ao conhecimento científico e à comunicação dessas explicações.

Outra proposta de ensino com a utilização de atividades investigativas é a de Azevedo (2006). Para essa autora, uma atividade de investigação, para que assim possa ser considerada, deve levar o aluno a refletir, discutir, explicar, relatar e não apenas se limitar a favorecer a manipulação de objetos e a observação dos fenômenos. Nesse sentido, a autora salienta que a aprendizagem de procedimentos e atitudes torna-se tão importante quanto a aprendizagem de conceitos ou do conteúdo.

A mesma autora enfatiza que as práticas de investigação devem contemplar alguns momentos que, segundo ela, devem ser: proposta do problema, preferencialmente em forma de pergunta que estimule a curiosidade científica do estudante; levantamento de hipóteses, que devem ser emitidas pelos alunos por meio de discussões; coleta de dados; análise dos dados obtidos, em que podem ser utilizados gráficos e textos, para que os alunos possam realizar a explicação desses dados; conclusão, quando os alunos formulam respostas ao problema inicial, a partir dos dados obtidos e analisados. Essas ideias são compatíveis com as apresentadas pelos demais autores como, por exemplo, Gil Perez (1996), Rodriguez, (1995) e Gil (1996).

Carvalho (2006) afirma que, para favorecer a construção de conhecimentos pelos alunos, os professores devem propor questões interessantes e desafiadoras aos mesmos para que, ao resolverem os questionamentos propostos, possam conhecer os enfoques próprios da cultura científica, promovendo um processo de enculturação. Nesse sentido, a autora classifica a atuação do professor e dos alunos em diferentes níveis de envolvimento com a atividade investigativa, e propõe uma graduação para estudar o que chama de grau de liberdade que os professores 
oferecem aos estudantes. Essa graduação é apresentada no quadro abaixo.

Quadro 2: Graus de liberdade professor/aluno na aula de laboratório

\begin{tabular}{c|c|c|c|c|c} 
& GRAU I & GRAU II & GRAU III & GRAU IV & GRAU V \\
\hline PROBLEMA & $\cdots$ & P & P & P & A/P \\
\hline HIPÓTESES & $\cdots$ & P/A & P/A & P/A & A \\
\hline $\begin{array}{c}\text { PLANO DE } \\
\text { TRABALHO }\end{array}$ & $\cdots$ & P/A & A/P & A & A \\
\hline $\begin{array}{c}\text { OBTENCূ̃̃ } \\
\text { DOS DÁDOS }\end{array}$ & $\cdots$ & A/P & A & A & A \\
\hline CONCLUSÃO & $\cdots$ & A/P/Classe & A/P/Classe & A/P/Classe & A/P/Sociedade
\end{tabular}

Fonte: CARVALHO, 2006. p, 83.

De acordo com Carvalho (2006), no grau I existe apenas a participação do professor na aula, não caracterizando um trabalho investigativo no qual os alunos têm a possibilidade de construir seus conhecimentos.

A partir do grau II, é possível observar enfoques que são próprios da cultura científica. Nesse nível de liberdade, o professor propõe o problema. A elaboração de hipóteses e o plano de trabalho são realizados pelos alunos, mas com a orientação do professor. O registro dos dados é também realizado pelos alunos com a orientação do professor, e a conclusão pode ser elaborada pelo grupo de alunos, mas apresentada e discutida por toda a sala, ressaltando a necessidade do conhecimento ser divulgado, assim como ocorre na Ciência. Segundo a autora, esse é um ponto relevante para a enculturação científica.

Já os níveis III e IV possibilitam mais liberdade aos alunos, e o nível V é o que se propõe nos cursos de mestrado e doutorado, em que o aluno pode pensar em um problema e solucioná-lo (CARVALHO, 2006). No quadro apresentado, a autora salienta a utilização de atividades investigativas práticas ou de laboratórios. Enfatizamos que atividades investigativas nem sempre precisam ser realizadas somente com a participação de experimentos ou demonstrações práticas. Bybee (2006) descreve uma atividade em que um professor de Ciências apresentou aos estudantes algumas fotografias da atmosfera da Terra nas quais apareciam numerosos buracos negros. O professor, então, levantou um questionamento sobre o que poderia ter provocado aqueles buracos na atmosfera. Por meio dessa atividade, os alunos desenvolveram uma investigação, não sendo qualificada como atividade experimental. Segundo o autor, os alunos estavam engajados na resolução do problema, observaram as evidências, formularam explicações a partir das evidências, relacionaram suas explicações ao conhecimento científico e, finalmente, apresentaram suas conclusões.

Uma visão mais recente, apontada por Duschl (2009), apresenta algumas alterações nas diferentes abordagens da utilização do laboratório didático e nas atividades investigativas no ensino, as quais seriam de uma imagem de educação 
científica para ensinar o que nós conhecemos, para uma educação científica que enfatiza o como nós conhecemos; de uma educação científica que salienta o ensino de conteúdos, para uma educação com ênfase na relação entre evidências e explicações; da demonstração de conceitos para o ensino que promove o raciocínio com e sobre os conceitos; de uma visão que salienta a observação e apenas a experimentação para uma visão que enfatiza a construção de modelos e a observação guiada por uma teoria ( DUSCHL, 2009).

Em síntese, as ideias deste autor ressaltam principalmente a utilização de atividades investigativas por meio do laboratório didático. Percebemos convergência entre a abordagem de Duschl, (2009) a de Watson (2004) e Newman (2004) quanto à priorização de evidências ao serem utilizadas atividades de investigação. Há também compatibilidade quanto à abordagem de Dushl (2009), com Azevedo (2006) e com Carvalho (2006) quanto à realização de demonstrações apenas em caráter ilustrativo para práticas que promovam o raciocínio dos alunos.

\section{CONSIDERAC̦̃̃ES FINAIS}

De acordo com o que foi exposto neste estudo e, considerando a visão de diferentes autores, é possível perceber maneiras distintas de se desenvolverem as atividades investigativas com os alunos, no que se refere às diferentes abordagens que tais atividades apresentam. Vimos que não há um consenso entre os pesquisadores desta área sobre esta perspectiva de ensino. No entanto, como apresentamos, existem abordagens com pontos de convergência no que se refere às características para atividades investigativas. Não há um consenso entre os pesquisadores desta área sobre esta perspectiva de ensino. Isso ocorre até mesmo nos Estados Unidos, país em que essa proposta é bastante incentivada. Essa mesma conclusão foi obtida por Sá et al ( 2009) em pesquisa desenvolvida com professores de Ciências por Investigação. Ainda quanto às diferenças nas abordagens dessas atividades, Sherin et al (2006) ressaltam que tais diferenças têm proporcionado nomenclaturas diferentes para o que os autores denominam de tarefas estruturadas, e que neste estudo forma tratadas como atividades de investigação.

Porém, em todos os casos, concorda-se que essas atividades são sempre baseadas em problemas que os alunos devem resolver e que esta proposta de ensino apresenta-se muito diferente da abordagem do ensino tradicional, no qual o professor tem a preocupação de desenvolver uma lista de conteúdos, muitas vezes de modo expositivo, sem proporcionar aos alunos uma reflexão mais profunda (SHERIN et al 2006).

Admitimos que as atividades de investigação permitem promover a aprendizagem dos conteúdos conceituais, e também dos conteúdos procedimentais que envolvem a construção do conhecimento científico. Concordamos que essas atividades, sejam elas de laboratório ou não, são significativamente diferentes das atividades de demonstração e experimentações ilustrativas, realizadas nas aulas de 
Ciências, por fazerem com que os alunos, quando devidamente engajados, tenham um papel intelectual mais ativo durante as aulas.

Consideramos que a apresentação do problema pelo professor é mais oportuna em nossas escolas, devido às condições do trabalho desenvolvido e ao número de alunos em nossas salas de aula. Sendo assim, a apresentação do problema pelos alunos individualmente dificultaria o desenvolvimento de tais atividades.

Apesar da polissemia associada ao termo atividades de investigação e da falta de consenso quanto às peculiares que as referidas atividades apresentam, admitimos que algumas características devem estar presentes nas atividades investigativas: o engajamento dos alunos para realizar as atividades; a emissão de hipóteses, nas quais é possível a identificação dos conhecimentos prévios dos mesmos; a busca por informações, tanto por meio dos experimentos, como na bibliografia que possa ser consultada pelos alunos para ajudá-los na resolução do problema proposto na atividade; a comunicação dos estudos feitos pelos alunos para os demais colegas de sala, refletindo, assim, um momento de grande importância na comunicação do conhecimento, tal como ocorre na Ciência, para que o aluno possa compreender, além do conteúdo, também a natureza do conhecimento científico que está sendo desenvolvido por meio desta metodologia de ensino.

\section{NOTA}

${ }^{1}$ Apoio CNPq, Fundação Araucária e FAEPE/UEL.

\section{REFERÊNCIAS}

AZEVEDO, M.C.P.S. Ensino por investigação: problematizando as atividades em sala de aula. In: . Ensino de ciências: unindo a pesquisa e a prática. Anna Maria Pessoa de Carvalho (Org). São Paulo. Thomson, 2006.

BAPTISTA, M.; CARVALHO, C.; FREIRE, S. \& Freire A. Investigações e práticas inclusivas no ensino das ciências. Um estudo com alunos em risco de abandono escolar. Actas do VI Encontro Nacional de Pesquisa em Educaşão em Ciências. Florianópolis (Brasil). (2007)

BARROW, L. H. A Brief History of Inquiry: From Dewey to Standards. In: Journal of Science Teacher Education, 2006, 17:265-278, Springer 2006.

BRASIL, Secretaria de Educação Fundamental.Parâmetros Curriculares Nacionais. $3^{\circ}$ e $4^{\circ}$ ciclos. Apresentação em Temas transversais. Brasília: MEC/SEF,1997.

BORGES, A. T. Novos rumos para o laboratório escolar de ciências. Caderno Brasileiro. Ensino de Física. v. 19, n.3: p.291-313, dez., 2002

BYBEE, R.W. Scientific inquiry and science teaching. In: FLICK; LEDREMAN. Scientific inquiry and nature of science. Implications for teaching, learning, and teacher education. Springer, 2006.

CARVALHO, A. M. P. Las practices experimentales en el proceso de enculturación cientifica . In: GATICA, M Q; ADÚRIZ-BRAVO, A (Ed). Enseñar ciencias en el Nuevo milenio: retos e propuestas. Santiago: Universidade católica de Chile.2006

CHALMERS, A.F . O que é ciência, afinal? São Paulo. Brasiliense, 2000.

DEBOER, G. E. Historical perspectives on inquiry teaching in schools. In: FLICK; LEDREMAN. Scientific inquiry and nature of science. Implications for teaching, learning, and teacher education. Springer, 2006.

DEWEY, J. Experiência e Natureza : lógica : a teoria da investigação: A are como experiência: Vida e 
educação: Teoria da vida moral. São Paulo: Abril Cultural, 1980.

DUSCHL.A,R. The HS Lab Experience: Reconsidering the Role of Evidence, Explanation and the Language of Science. Disponivel em http://www7.nationalacademies.org/bose/RDuschl_comissioned_paper_71204_HSLabs_Mtg.pdf. Acesso em dezembro de 2009.

GIL, D. Contribuición de la historia y de la filosofiade las cienciasal dessarollo de um modelo de enseñanza/aprendizajecomo investigación. Enseñanza de las Ciências, 11(2), 1993

GIL PEREZ, D. VALDES CASTRO, P. La orientación de las practices de laboratorio como invetigagación: un ejemplo ilustrativo. Enseñanza de las ciencias, 14 (2), 1996.

GOUVEIA, G; LEAL, M.C. Uma visão comparada do ensino em ciência, tecnologia e sociedade na escola e em um museu de ciência. In: Revista Ciência e educação, vol 7, número 1, 2001.

ISKANDAR, Jamil Ibrahim; LEAL, Maria Rute. Sobre o positivismo e Educação. In: Revista Diálogo Educacional, Curitiba, v. 3, n.7, p. 89-94, set./dez. 2002.

NEWMAN Jr. W. J; ABEL. S. K, HUBBARD. P. D; MC DONALD. J. (2004) Dilemmas of teaching inquiry in elementary science methods. Journal of Science teacher education 15(4).

RODRIGUEZ, J et al. ¿Cómo enseñar? (1995) Hacia una definición de las estratégias de enseñanza por investigación. Investigación em la escuela, n. 25.

ROSITO, B. A. O ensino de ciências e a experimentação. In: MORAES, R (org). Construtivismo e ensino de ciências: reflexões epistemológicas e metodológicas. Porto Alegre, EdiPUCRs, 2008.

SÁ, E. F. de, PAULA, H. de F, LIMA, M. E. C.; AGUIAR, O. G. de. As características das atividades investigativas segundo tutores e coordenadores de um curso de especialização em ensino de ciências. In: Encontro Nacional de Pesquisa em Ensino de Ciências, 6, Florianópolis, SC, Atas..., 2007.

SÁ, Eliane Ferreira de. Discursos de professores sobre ensino de ciências por Investigaşão. Tese de DoutoradoBelo Horizonte: UFMG/FaE, 2009.

SANTOS, W. L.. Educação científica na perspectiva de letramento como prática social: funções, princípios e desafios. In: Revista brasileira de educação. v. 2 n 36, set/dez. 2007.

SHERIN, B. EDELSON, D. BROWN, M. On the content of task- strutured science curricula. In:__ Scientific Inquiry and nature of science: implications for teaching, lerarning, and teacher education. Springer, 2006.

WATSON, F. Road. Student's discutions in practical scientific inquiries. In: International Journal Science education. January, vol , 26. no 1, 25-45, 2004.

WONG, D . PUGH, Kevin.(2001) Learning Science: A Deweyan Perspective In:

Journal of research in science teaching. VOL 38, No 3, P 317-336

Data de Recebimento: 13/05/2010

Data de Aprovação: 14/02/2011

Data da Versão Final: 27/08/2011 